Rhode Island College

Digital Commons @ RIC

Master's Theses, Dissertations, Graduate

Master's Theses, Dissertations, Graduate

Research and Major Papers Overview

Research and Major Papers

2013

\title{
Evaluating the Effectiveness of Concurrent Review
}

Celia Gomes McGillivray

Rhode Island College

Follow this and additional works at: https://digitalcommons.ric.edu/etd

Part of the Nursing Commons

\section{Recommended Citation}

McGillivray, Celia Gomes, "Evaluating the Effectiveness of Concurrent Review" (2013). Master's Theses, Dissertations, Graduate Research and Major Papers Overview. 159.

https://digitalcommons.ric.edu/etd/159

This Major Paper is brought to you for free and open access by the Master's Theses, Dissertations, Graduate Research and Major Papers at Digital Commons @ RIC. It has been accepted for inclusion in Master's Theses, Dissertations, Graduate Research and Major Papers Overview by an authorized administrator of Digital Commons @ RIC. For more information, please contact digitalcommons@ric.edu. 


\section{EVALUATING THE EFFECTIVENESS OF CONCURRENT REVIEW}

by

Celia Gomes McGillivray

A Major Paper Submitted in Partial Fulfillment

of the Requirements for the Degree of

Master of Science in Nursing

in

The School of Nursing

Rhode Island College

2013 
Evaluating the Effectiveness of Concurrent Review

Celia Gomes McGillivray, MPH, BC-RN, CHES

\section{Author Affiliation:}

Quality Management Department, The Miriam Hospital, Providence, RI.

\section{Corresponding Author:}

Celia Gomes McGillivray, 139 Arnold Avenue, Cranston, RI 02905

Telephone: 401-941-1197; email:celiagm@,verizon.net; cgomesmcgillivray@lifespan.org Acknowledgment: The author would like to thank Cynthia Padula, Ph.D, RN, Rhode Island College, for her guidance and consultation, and William Anger, MLIS, The Miriam Hospital, for providing additional literature searches. Neither of these individuals received any compensation for their assistance.

No conflicts of interest are declared.

No disclosure for funding.

The research study received IRB approval from Lifespan and Rhode Island College

Key words: concurrent review, performance feedback, audit and feedback 
Table of Contents

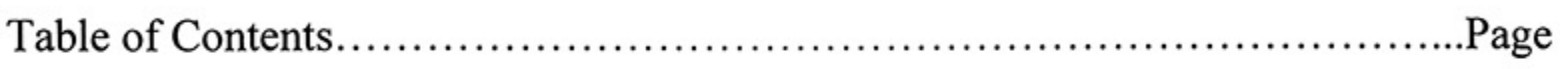

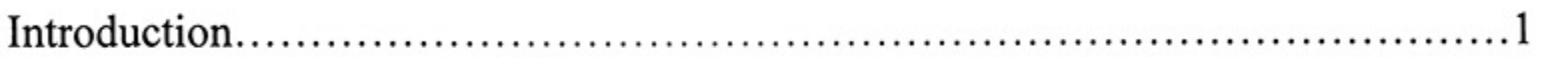

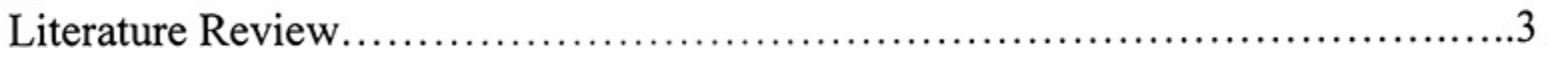

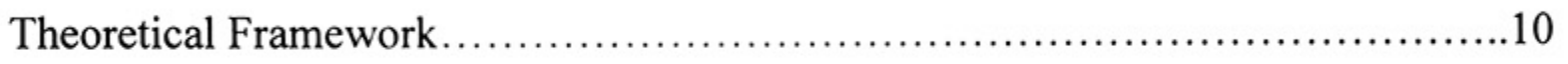

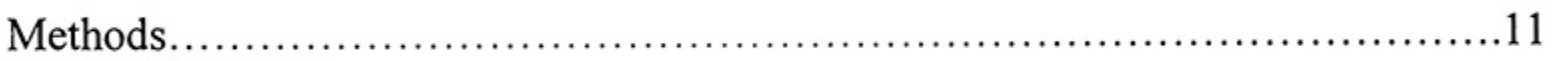

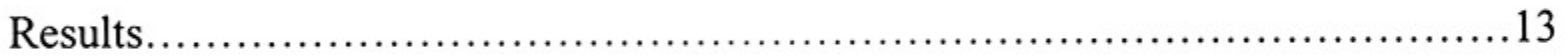

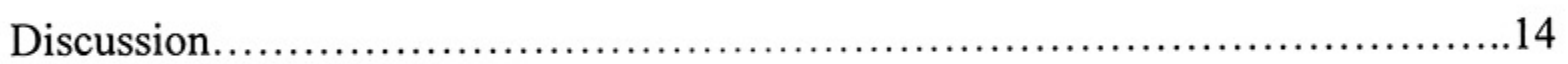

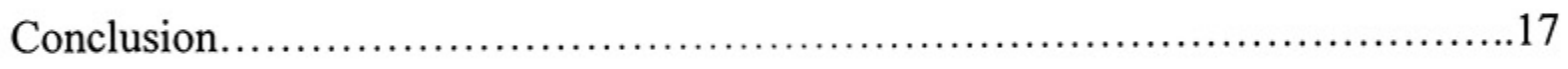

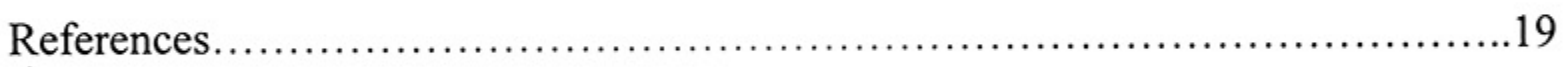

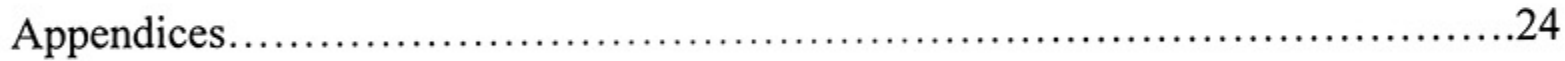




\section{Introduction}

The United States (US) health care delivery system, which is under intense scrutiny, requires fundamental changes in order to improve patient safety. ${ }^{1,2}$ Advances in health care such as advanced diagnostic equipment, robotics, and other technology have transformed the provision of care; however, it is unclear whether the quality of care has improved. ${ }^{1}$ It has been questioned as to whether clinicians in the US provide a high quality of care, are able to deliver it consistently, in a standardized manner, and have incorporated evidence based research in the delivery of medical care. ${ }^{2}$ Too much variation in the health care service delivery has contributed to rising health care costs, and attempts to constrain the increase have been largely unsuccessful despite implementation of various strategies. ${ }^{1}$ Federal agencies and health insurers have implemented mechanisms that included capitation, utilization review, case management, preauthorization, and limiting panel sizes. ${ }^{3}$ These strategies have been largely directed at physicians who are considered the major decision makers regarding health care and health care delivery. ${ }^{3}$

At the same time that cost containment strategies were being implemented, the Agency for Health Care Research and Quality (AHRQ) encouraged health care organizations to incorporate quality improvement to improve health care. ${ }^{4}$ Deming's PDSA cycle of Plan, Do, Study, Act, and Wagner's Chronic Care Model were recommended by the Institute of Health Care Improvement (IHI) to accelerate changes in health care delivery systems. ${ }^{5,6}$ Contributing to the national discussion, The Centers for Medicare and Medicaid (CMS) considered clinician reporting and value based purchasing initiatives as a way of rewarding clinical performance, but did not change policy. ${ }^{7}$ 
Under the guise of quality improvement, other mechanisms surfaced to help change process and outcome health care measures. ${ }^{8}$ Audit and feedback, academic detailing, opinion leaders, performance feedback, physician reminder systems, clinical decision support aids, incorporation of medical guidelines into protocols, and computerized physician order sets have been used to drive physician behavior change.

In 2001, The Institute of Medicine (IOM) published "Crossing the Quality Chasm: A New Health System for the $21^{\text {st }}$ Century". 9 This report cited deficiencies in the health care delivery system and called for improvement in six dimensions of health care performance. This and subsequent IOM reports highlighted patient safety as a critical element of health care. ${ }^{9}$ They identified six dimensions of patient safety, which became the main indices for quality improvement initiatives. CMS eventually created the Physician Quality Reporting System, the eprescribing Incentive Program, and the electronic health record (EHR) Incentive Program for Medicare and Medicaid, all of which are types of mechanisms that support the IOM recommendations to achieve patient safety goals. ${ }^{10}$ Health care organizations began to evaluate more aggressively how quality improvement strategies could improve their health outcome measures in response to the external pressure of public reporting of quality measures and predicted cuts in reimbursement tied to quality measures.

Concurrent review may be seen as a relatively new quality improvement strategy or an improvement over an existing quality improvement strategy, but research is scant. This strategy incorporates several key elements of performance feedback, which may be broadly defined as sharing non-judgmental information to professionals regarding discrepancies between their actual performance and standards of care. ${ }^{11}$ The distinction between concurrent review and 
performance feedback is the timing of information provided. Concurrent review incorporates the provision of medical information regarding a provider's performance during the patient's hospitalization, so that the plan of care is altered. This study evaluated concurrent review by examining the impact on stroke measures and whether physician and nurse practice patterns in managing stroke patients were altered.

\section{Literature Review}

Literature for the time period of 1995-2011 was searched in the electronic databases of CINAHL and Medline (Pub Med) using the key words real time feedback, performance feedback, concurrent review, audit and feedback, utilization review, case management, trigger tools, and stroke measures. A total of 48 articles were selected that identified how quality improvement strategies influence physician practice patterns and in what ways clinical and quality measures were impacted. With the exception of one case study, no articles regarding concurrent review were identified. Therefore, the related topics of audit and feedback and performance feedback were selected because of the common characteristics that define these strategies and that are shared with concurrent review.

\section{Audit and Feedback}

Audit and feedback, considered a quality improvement strategy, have been used to alter physician practice patterns involving utilization, laboratory practices, prescribing patterns, or patient outcomes, such as blood pressure, glycemic control, or lipid panel management. ${ }^{12,13}$ Feedback is defined as non-judgmental sharing of information regarding discrepancies between actual performance and medical standards of care. It is based upon a belief that physicians might modify their practice behaviors if the feedback given on their clinical performance were 
compared with peers' performance and with an accepted set of set of standards. ${ }^{12,13}$ Although audit and feedback are widely used as a continuous quality improvement mechanism to improve process and outcome health measures, uncertainty about the effectiveness and the specific characteristics that lead to improvement remains. ${ }^{14}$

\section{Summary of Meta-Analyses}

Several meta-analyses regarding audit and feedback have been conducted to demonstrate how physician practices are impacted after implementation of this intervention. Physicians are mandated by the American Medical Association to participate in life long, self directed learning that involve CME educational activity. In a systematic review ${ }^{15}$ that included 20 comparisons between self-assessment and external assessment about physician practices regarding utilization of resources or prescribing practices, the majority showed little, no, or an inverse relationship between $\mathrm{CME}$ education and changes in practice. Another systematic review ${ }^{13}$ was conducted to evaluate the effectiveness of educational interventional strategies on physician behaviors including such activities as CME activities, outreach visits, academic detailing, use of opinion leaders to deliver performance information, audit and feedback, and personal reminders. Ninetynine trials with 160 interventions were evaluated. In findings relevant to this study, ten positive outcomes and 14 negative outcomes were identified related to audit and feedback. Outcomes were more consistently effective when the intervention was feedback in the form of chart review.

A meta-analysis ${ }^{13}$ was conducted to evaluate the effect of audit and feedback on healthcare professional practices and patient outcomes. A Cochrane review examined 70 studies and 108 comparisons that identified audit and feedback as a core component and evaluated effects on professional practice. The exploratory analyses examined the likelihood that audit and 
feedback would improve professional practice target behaviors such as prescribing patterns, laboratory utilization, and diabetes or cardiovascular disease management. Estimated effects across inpatient $(\mathrm{RD}=7.7 \%)$ and outpatient settings $(\mathrm{RD}=7.1 \%)$. were very similar. When targeted behavior was added to the meta-regression model, the model was statistically significant $(\mathrm{p}<0.0001)$. No significant differences in effectiveness of various feedback mechanisms, including delivered by mail, voice, or in person were detected. As in an earlier review ${ }^{16}$ of audit and feedback, baseline performance was inversely associated with the effectiveness of audit and feedback. The meta-regression provided indirect evidence that audit and feedback may be most effective when performance is low from the beginning; the originator of the feedback is the supervisor or a colleague; the feedback is repeated at least monthly; and the message contains specific targets or benchmarks. The authors concluded that audit and feedback led to small yet important improvement in the health practices, and that providers will alter their practice when the performance feedback is consistent with the standard of care.

Information feedback may be defined as reporting on past patient care activities to influence future clinical decisions. Feedback, designed to build consensus among physicians, influences clinical decision making and autonomy. ${ }^{17}$ A multi-level meta-analysis ${ }^{17}$ was conducted to assess the clinical effect of a peer-comparison feedback intervention in changing practice patterns. Twelve randomized controlled trials involving 521 physicians were included in the analyses. The results documented a statistically significant $(\mathrm{p}<0.05)$ modest effect of peer comparison feedback on utilization of various clinical procedures. The authors concluded that there was a need for controlled clinical evaluations before physicians are required to utilize certain management interventions. 


\section{CME Educational Sessions}

A systematic review ${ }^{15}$ was conducted to examine the effectiveness on physician practice performance of different strategies such as $\mathrm{CME}$, audit and feedback, computerized decision support systems, or multifaceted interventions for nurses and primary health care providers. Eighteen studies met the inclusionary criteria and five were included in the meta-analysis. Modest improvements were observed after the passive dissemination of information such as via CME programs. Computerized decision support systems led to improvement regarding drug dosing, providing preventive care, and clinical management. When two or more interventions were conducted, such as with reminder systems and interactive educational meetings, more improvement was observed than when single interventions were utilized. Insufficient evidence existed to evaluate opinion leader effectiveness on clinical practice patterns.

CME programs that incorporate clinical practice guidelines may be effective in changing provider practice. Clinical practice guidelines assist clinicians with decisions about appropriate care for special patient circumstances; however, passive distribution of this information is less effective. ${ }^{18}$ One study evaluated changes in provider knowledge and practice following an educational session on stroke guidelines. ${ }^{19}$ Physicians stated that they knew more and scored higher (2.62 logits or $89 \%$ ) than non-physicians on an initial knowledge test (2.35 logits or $87 \%$; $\mathrm{t}$ test value of $594=3.27, \mathrm{p}<0.01)$. Attendance at a lecture on stroke guidelines was not associated with an increase in knowledge or a change in physician practice. There was no change in knowledge over time nor did doctors retain more information than non-doctors. The authors concluded that physician behavior change is a complicated process and may be influenced by 
providing individual follow-up, allowing more time for the interaction, and assuring that a high level of clinical evidence is provided.

One study used a unique approach for influencing physician behavior by using money as an incentive. Money can influence physician behavior, but few trials have shown improved performance as an outcome. ${ }^{1}$ One study examined community physician offices and rates of influenza immunizations when economic incentives were introduced. The median practice improvement immunization rates were $+10.3 \%$ higher in the economic incentive group than in the control group $+3.5 \%$ without economic incentives. ${ }^{20}$

\section{Standardized Order Sets}

The California Acute Stroke Pilot Registry (CASPR) ${ }^{21}$ study examined the effect of standardized order sets and registry monitoring on six measures of stroke care. Optimal treatment was defined as those who received care in five areas: VTE/DVT prophylaxis by end of hospital day two; anti-thrombotics after hospital day two and prescribed at discharge; documentation for tissue plasminogen activator (tPA) eligibility; statins prescribed at hospital discharge; and counseling provided for tobacco cessation. A total of 413 ischemic stroke patients' medical records were evaluated at six hospitals that implemented the standardized order sets. More patients received optimal care (63\%) post-intervention as compared to pre-intervention (44\%). Four of the six hospitals experienced improvement in the delivery of optimal stroke care treatment, but the authors could not determine if the change was related to implementation of standardized order sets.

\section{Performance Feedback}


Performance feedback is the delivery of specific information that contains trends on individual behavior with comparisons to peer behavior on a particular practice pattern. The impact of direct feedback given to medical students after an intervention was compared to a practice based learning exercise. ${ }^{22}$ Medical students $(N=280)$ completed a self assessment of their own performance after they participated in a practice based learning exercise. Then, the medical students watched a video and re-assessed their performance. Mean clinical performance examination scores ranged from $51 \%$ to $71 \%$ of overall correct items and for each skill area. Self assessment scores correlated weakly with student performance ratings $(r=0.01)$. Correlations with feedback $(r=0.13)$ were weak as compared to without feedback $(r=0.20)$.

In a randomized control trial ${ }^{23}$ that studied the effect of performance feedback on tracheal suctioning knowledge, nurse retention of knowledge and skills improved when tailored feedback on performance was given during nurse tracheal suction as an intervention on nursing practice. The report studied whether individualized performance feedback improved knowledge and the clinical practice of tracheal suctioning. Ninety five healthcare professionals in two acute care hospitals were randomly allocated to receive either individualized performance feedback or no additional feedback after a standardized lecture and practical demonstration. Knowledge and the clinical practice of tracheal suctioning, the outcome measures, were assessed by self report and structured observation. The intervention subjects who received the individualized feedback performed better in terms of knowledge $(p=0.014)$ and practice $(p=0.037)$ at follow up. Those who received performance feedback scored significantly higher on knowledge $(p=0.004)$ and practice scores $(p=0.01)$ than the control group. 
A clustered $\mathrm{RCT}^{24}$ was conducted to evaluate the effect of performance feedback on stroke care quality, defined as adherence to stroke clinical guidelines. The stroke measures included: door to drug administration time for tPA; aspirin within 48 hours; provision of smoking cessation counseling; and early mobilization. Significant intervention effects were observed in stroke care in the critical care units $(\mathrm{OR}=2.7: 95 \% ; \mathrm{CI}=1.3-5.5 ; \mathrm{p}=0.007)$ and in medical surgical units $(\mathrm{OR}=1.5,95 \% \mathrm{CI}=1.3-1.7 ; \mathrm{p}<0.0001)$, but not during discharge care planning. The study did not detect an intervention effect on quality of care in the experimental or control group hospitals. The lack of effect could indicate that the intervention was less effective, the implementation was incomplete, or other trends impacted the results. ${ }^{24}$ The Capture Stroke Study ${ }^{25}$ examined whether feedback given on stroke measures (e.g., antiplatelets given at the end of hospital day two or statins prescribed at patient discharge) caused a change in physician practices as observed through improved documentation. The differences in the adjusted means for stroke outcome measures were not significant in the hospitals where feedback was provided as compared to the hospitals where feedback was withheld, with the exception of lipid screening completed.

Providing a one-time only confidential feedback on quality improvement data was not sufficient to stimulate a change in physician performance. The study supported the premise that providing timely clinical information to physicians could be beneficial and might prompt clinician improvement. The authors reported a need for studies that evaluate the effectiveness of interventions that improve the quality of stroke care.

\section{Concurrent Review}

Concurrent monitoring and data collection provide an opportunity to impact patient care at the time the care is being delivered. A case study ${ }^{26}$ examined two Florida hospitals that 
implemented concurrent review and evaluated the impact of the intervention on stroke performance measures. Out of eight stroke center measures, hospitals reported performing at $100 \%$ on four of the indicators and greater than $90 \%$ on another four. The hospitals saw the most impact as a result of concurrent monitoring versus retrospective reporting. While there may have been other factors affecting results, the fact that several hospitals improved on stroke measures suggested that providing feedback during the hospital stay was beneficial.

The literature supports the fact that feedback, when given frequently enough, by the right person, with the right message, can improve health care outcome measures. ${ }^{12}$ Concurrent review can be viewed as an enhancement to an existing quality improvement strategy of audit and feedback. The main difference is that the message is directed to the responsible physician or nurse in real time while the patient is hospitalized.

\section{Theoretical Framework}

Many theories and approaches have been used to examine influencers of physician and nurse practice performance and impact on quality of health care. Roger's Diffusion of Innovations, ${ }^{27}$ developed from social influence and power theories in the 1960 s, was selected to guide this research. Diffusion theory has been studied for many years in a variety of settings because of its versatility in examining how ideas become adopted. The adoption process can be very difficult, even when the potential user understands the benefit of the innovation. Gaps often exist between what is known and what is put into use. Many innovations can take years from introduction of the product to adoption into the mainstream marketplace. The major barrier to adoption is the speed at which the innovation has been adopted or integrated. ${ }^{27}$ 
Even though an individual may not have expressed an opinion on a particular innovation, the perception of the innovation may be inferred from his/her knowledge about the innovation or decision to adopt and use the innovation. Rogers classified members into innovators, early adopters, early majority, late majority, and laggards, and the degree to which an individual adopts a new idea in relation to others determines the rate of adoption. Personal characteristics may impact how fast an individual adopts a practice. Some individuals may choose not to stay abreast of advances, but rather to rely on the examples set by early adopters. Opinion leaders need to be early adopters to speed the rate of diffusion. ${ }^{28}$

Audit and feedback help physicians self assess because they may not be aware of their own sub-optimal performance relative to standards that they have not yet adopted. The rate of change of adoption may quicken if clinicians know their peers' are performing at the higher standard, because they consider their peers to be opinion leaders. ${ }^{1}$

\section{Methods}

\section{Design}

This study employed a retrospective, case-control, pre-post intervention and was conducted via review of nearly 400 records covering a period of five years. Changes in stroke measure outcomes data were compared pre-implementation and post-implement at one site; a control site was selected as a comparison. Differences in the stroke measure outcomes over the same time period were compared. The intervention, concurrent review, was initiated at the intervention site in June 2008, following the hiring of a stroke coordinator. Concurrent review was not implemented in the control site during the study period of June 2006 - May 2010. 
Concurrent review was designed to provide immediate feedback to physicians, advanced practice nurses, registered nurses, and other allied health care professionals who provided care to stroke patients in the hospital, and to assist them with adherence to national stroke guidelines and standards of care. The concurrent review process provided immediate feedback while the patient is in the hospital and results could be observed by tracking stroke related quality indicators. It was thought that through a collaborative effort, members of the clinical team would appreciate the reminders and respond accordingly by making necessary changes to the patients' care plan. The primary method for concurrent review became a daily examination of admitted patients with stroke and an established plan for providing feedback to the clinicians daily on their patient care management plans. This work was conducted by the stroke coordinator.

The independent variable, concurrent review, was controlled by measuring the effect on the dependent variables, selected stroke measures (Table I).

\section{Sites and Sample}

The two hospital sites were located in Providence, Rhode Island. The intervention site was a medium size community based teaching hospital and the control site was s a large academic medical center. Inclusion criteria included: patients discharged with an IDC-9-CM principal diagnosis code of ischemic stroke; age greater than 18 years; and length of stay less than 120 days. Exclusion criteria included: less than 18 years of age; lengths of stay greater than 120 days; comfort measures upon admission or during the hospital stay; enrolled in clinical trials; only admitted for an elective carotid intervention; discharged to another hospital; left against medical advice; and patients who expired

\section{Procedures}


This research project received IRB approval from the Lifespan IRB as well as the RI College IRB. All cases that met the ICD codes for ischemic stroke for the time period of January 2005 to May 2010 were selected. The charts were identified by using a simple random selection, and then reviewed for inclusion and exclusion criteria. Charts representing the pre-intervention time period (before concurrent review was implemented) were derived from eligible cases admitted between January 2005 to May 2008 for the intervention site and control site. The postintervention time period was between June 2008 and May 2010, the time that concurrent review was implemented at the intervention site only and charts were selected during this time period for the intervention site and the control site. All eligible cases were assigned a number and sample cases were randomly selected until the desired number of cases was achieved.

\section{Measurement}

A data abstraction tool was developed by the researcher after a careful review of other standardized stroke data abstraction tools. If any data elements were not documented in relation to the stroke measure, it was identified as a 'no'. Other data collected included selected demographics, insurance status, number of co-morbid conditions related to cardiovascular diseases, and length of stay.

\section{Data Analysis}

Descriptive statistics were used to examine the study variables. Inferential statistics appropriate to the data examined differences between the groups on selected stroke measures.

\section{Results}

Table II describes the characteristics for the intervention site and control site. The sample size was 174 for the intervention site and 177 for the control site $(\mathrm{N}=351)$. Patient 
characteristics were similar between the intervention site and control site during the pre and post intervention time periods. The mean age was 73 at the intervention site and 68 at the control site. Illness severity, defined as number of co-morbid conditions related to cardiovascular disease, was two for the intervention site and the control site. Both sites had nearly equal representation by gender during the pre and post intervention time periods. Most people were insured at the intervention and control sites during the pre and post intervention periods $(\mathrm{I}=95 \%$ pre vs. $98 \%$ post; $\mathrm{C}=92 \%$ pre vs. $95 \%$ post $)$. Table III illustrates the stroke measure results during the preintervention and post intervention period by site. The pre-intervention stroke measure data at the intervention site and control site were very similar for: dysphagia screening (1.8 vs. 1.9); NIHSS conducted (1.7 vs. 1.8); thrombolytic therapy administration or noted as contraindicated (2.4 vs. 2.5$)$; statins at discharge ( 1.3 vs. 1.3$)$. The results varied more for stroke education (1.3 vs. 1.6) and VTE (1.4 vs. 1.2), though differences were still comparatively small. Significant differences were observed post-intervention in the intervention site as compared to the control site on eight measures, including: dysphagia screening; NIHSS completed; tPA administered; tPA administered in three hours; contra-indications noted for tPA when not administered; statins prescribed at discharge; stroke education given to the patient and family prior to discharge; VTE/DVT addressed by end of hospital day two. Non-significant differences were detected for anti-platelets prescribed at discharge, patients with atrial fibrillation and prescribed anticoagulants, and anti-platelets administered by day two of the hospital stay.

\section{Discussion}

Though the two study sites were markedly different in terms of bed size and number of stroke cases managed, the two study sites were strikingly similar in patient characteristics. One 
surprising finding was that the number of insured subjects was quite similar between the two sites. Given that the control site tends to be identified as the major provider of 'free' health care in the state, a higher percentage of uninsured was anticipated. Statistically significant improvement in adherence to stroke outcomes measures was realized for eight of the 11 measures at the intervention site post intervention period. The provision of clinician feedback while patients were hospitalized impacted physician practices related to prescribing medication, as well as nursing practice related to dysphagia screening and providing stroke education. It can be reasonably assumed that stroke care improved at the intervention site during the post intervention period through the consistent adherence to the stroke guidelines and the delivery of the care by the clinician. No other significant, stroke-related practice changes were introduced during the study period. Though further study is indicated, based on this study it can be suggested that concurrent review can be an effective intervention to improve stroke care delivery. It is important to recognize that feedback is necessary, valuable, and vital to improving clinical care. ${ }^{11}$ Feedback when providing appropriately, and in a timely manner, can and does impact physician practice and even more so when benchmark information is provided. ${ }^{13}$ The goal of providing feedback to improve quality of care, ensure the consistent delivery of care, and adherence of clinical guidelines can be achieved.

The use of opinion leaders ${ }^{14}$ as supported by Roger's theory ${ }^{27}$ seemed to be an effective component of this intervention. The stroke coordinator might be conceptualized as a change agent, working along with opinion leaders including physicians, medical directors, physician administrators, and nurse leaders. Opinion leaders can be very influential in shaping views and impacting adherence to conforming to standards. It is believed that this support strengthened the 
effect of concurrent review and may have influenced the physicians and nurses to appropriately respond to the feedback provided by the stroke coordinator. Another type of opinion leader external to a hospital organization is The Joint Commission. This organization can and does influence care practices with the weight of providing accreditation for health care organizations.

As with many studies, this study has several limitations. External influences may have prompted health care organizations to improve their system of delivery regarding stroke management. For example, during the time period of 2005-2010, The Joint Commission promoted disease specific designations specific to stroke as a way for hospital organizations to improve quality of hospital care and required measurement of key stroke measures. ${ }^{29}$ At the same time of the disease specialty certifications offered by TJC, the AHA/ASA published a landmark document regarding stroke management guidelines. ${ }^{30}$ This publication may have influenced the two participating hospitals' physician practices patterns; for example, no measureable change in prescribing antiplatelets at day two and discharge and in prescribing anticoagulation with atrial fibrillation was detected at either site during the pre and post intervention period. Physicians were already adherent to this practice and the national guidelines may have been the reason for conformity. The Stroke Act of 2009 legislated that all RI hospitals participate in the AHA/ASA's Get with the Guidelines (GWTG) stroke program. ${ }^{31,32}$ The Act directed emergency medical service providers to bypass hospitals that were not stroke certified and required all licensed hospital facilities to participate in the stroke program. This legislation may have driven hospitals to participate in AHA/ASA GWTG program for want of being managing these patients, understanding that data sharing would be a part of the program as 
dictated by the Department of Health. External influences can be just as influential as internal priorities in organizations changing their systems of care to improve care.

\section{Conclusion}

Providing immediate feedback, via the process of concurrent review, to the responsible physician and responsible nurse while the patient remains hospitalized was demonstrated to be an effective strategy as evidenced by positive change in stroke measures. Concurrent review incorporated with other interventions such as educational material, use of opinion leaders, or face to face interaction results in greater benefits. ${ }^{12}$ Concurrent review is an intervention that can make measureable difference in stroke measures and influence physician and nursing practices as it relates to stroke care management. However, efforts to change physician and advanced nurse practice regarding provider prescribing patterns must be targeted at specific behaviors, and must also distinguish between process and outcome measures. Changes in systems of care may be more influential in impacting process measures such as adherence to standards of care for stroke management. Improvement in outcome measures such as mortality, re-admission rates, or hospital acquired conditions may be more difficult to attain.

With the use of technology and sophisticated medical management systems such as mandatory orders pre-checked, computerized reminder systems have evolved and become integrated into the delivery of care. The laborious task of providing feedback to licensed independent practitioners and registered nurses will soon be available with a click of the mouse. Information will be utilized at the time a clinical decision is made and automatic prompts will flag the providers when a standard of care has not been met. With the advent of The 2009 American Recovery and Reinvestment Act, that provides financial incentives for hospitals and 
eligible providers to demonstrate "meaningful use" of health information technology, hospitals have improved how health data is captured and reported. Concurrent review as implemented in the intervention site is a resource intensive process where daily reminders are given to clinicians on ways to improve their stroke management. Although the study proved that the intervention was effective in improving stroke measures having to do with prescribing medication and delivery of stroke education, with the increased emphasis on technology, health care organizations may utilize IT for helping to make improvements in care by electronically sending prompts to clinicians who have not met the standard of care.

Concurrent review is a quality improvement that offers an opportunity for hospitals to maximize their reimbursement from CMS, since stroke measures are part of the core measure set requirement for reporting. The resource intensive intervention used in this study may be difficult to implement in some health care organizations, but when combined with the use of relevant technology as well as incentives, concurrent review potentially offer the capacity to improve stroke outcome measures. 


\section{References}

1. Smith W R. Evidence for the effectiveness of techniques to change physician behavior. Chest. 2000. doi: 10.1378/chest.118.2_suppl.8S

2. Resar R K, Rozich J D, Classen D. Methodology and rationale for the measurement of harm with trigger tools. Qual Safe Health Care. 2003; 12(supp lII):39-ii45.

3. Flynn, K. E., Smith, M. A., \& Davis, M. K. (2002). From physician to consumer: the effectiveness of strategies to manage health care utilization. Medical Care Research and Review, 59(4), 455-481. (Author manuscript: NIH Public Access)

4. Agency for Healthcare Research and Quality. AHRQ at a glance. AHRQ Publication No. 09-P003. Rockville, MD. Agency for Healthcare and Quality. September 2010. http://www.ahrq.gov/about/ataglance.htm. Accessed November $17,2010$.

5. Deming W E. The New Economics. Cambridge, Mass: MIT Press. 1993

6. Bodenheimer T, Wagner E H, Grumbach $\mathrm{K}$. Improving primary care for patients with chronic illness. The chronic care model part 2. JAMA. 2002; 288 (15):19091914.

7. Rosenthal MB, Landon BE, Normand SL, Frank RG, Epstein AM. Pay for Performance in commercial HMOs. N Engl J Med, 2006; 355:1895-1902

8. Layde P, Meurer L, Guse C, Yang H, Laud P, Meurer et al. Confidential performance feedback and organizational capacity building to improve hospital patient safety: results of a randomized trial. Funding of work: \#U18HS118993 from AHRQ and grant R49/CCR519614 from CDC. 
9. Committee on Quality of Health Care in America. Washington, D.C. Institute of Medicine.2001. Crossing the quality chasm, a new health system for the $21^{\text {st }}$ century. National Academy Press. ISBN 0-309-07280-8.

10. Health Care Affairs' Regulatory Round-Up. AAMC; Fall 2011.

11. Ende J; Feedback in clinical medical education. JAMA 1983; 250(6):777-781

12. Bours, G., Halfens, R., Candel, M., Grol, R. A pressure ulcer audit and feedback project across multi-hospital settings in the Netherlands. International Journal for Quality in Health Care. 2004; 16 (3): 211-218.

13. Ivers N, Jamtvedt G, Flottorp S, Young J M, Odgaard-Jensen J, French SD. et al . Audit and feedback: effects on professional practice and healthcare outcomes (Review). The Cochrane Collaboration. 2012; John Wiley \& sons, Ltd.

14. Davis DA, Thomson MA. Oxman AD. Haynes RB. Changing physician performance. A systematic review of the effect of continuing medical education strategies. JAMA. 1995; 274 (9): 700-705

15. Davis DA, Mazmanian PE, Fordis M, Van Harisson R, Thorpe K E, Perrier L. Accuracy of physician self-assessment compared with observed measures of competence. JAMA. 2006; 296 (9): 1094-1102.

16. Bero LA, Grilli R, Grimshaw J, Harvey E, Oxman AD, Thomason MA. Effective professional practice and organization of care module. Cochrane data base of systematic reviews. The Cochrane Library. The Cochrane Collaboration: Issue 4: Oxford, Update Software 1997. 
17. Balas EA, Boren SA, Brown GD, et al. Effect of physician profiling on utilization: meta-analysis of randomized clinical trials. J Gen Intern Med, 1996; 11:584-590.

18. Bero LA, Grilli R, Grimshaw JM, Harvey E, Oxman AD, Thomson, MA. Closing the gap between research and practice: an overview of systemic reviews of interventions to promote the implementation of research findings. $B M J, 1998$, $317 ; 465-468$.

19. Heinemann A W, Roth E J, Rychlik K, Pe K, King C, Clumpner J. The impact of stroke practice guidelines on knowledge and practice patterns of acute health professionals. J Eval Clin Prac, 2002; 9(2), 203-212.

20. Kouides RW, Bennett NM, Lewis B, Cappuccio JD, Barker WH, Laforce FM. Performance-based physician reimbursement and influenza immunization rates in the elderly. The primary-care physicians of Munroe County. Am J Prev Med., $1998 ; 14(2): 89-95$.

21. California Acute Stroke Pilot Registry Investigators. The impact of standardized stroke orders on adherence to best practice. Neurology, 2005; 65, 360-365.

22. Srinivasan M, Haurer K E, Martirosian C D, Wilkes M, Gesundheit N. Does feedback matter? Practice based learning for medical students after a multi institutional clinical performance examination. Med Ed, 2007; 41, 857-865.

23. Day T, Iles N, Griffith P. Effect of performance feedback on tracheal suctioning knowledge and skills: randomized controlled trial. $J$ Adv Nurs, 2009;65(7), 14231431. doi: $10.1111 / \mathrm{j} .1365-2648.2009 .04997 . \mathrm{x}$ 
24. Lakshminarayan K, Borbas C, Mclaughlin B, Morris N E, Vazquez G, Luepker R. A cluster randomized trial to improve stroke care in hospitals. Neurology, $2010 ; 74,1634-1642$.

25. Pandey D K, Cursio J F. Data feedback for quality improvement of stroke care. Am J Prev Med, 2006;31, 224-229. doi: 10.1016/j.amepre.2006.08.006

26. American Stroke Association/American Heart Association. Get With The Guidelines. Case study: concurrent data collection. American Stroke Association. American Heart Association. 2005.

27. Rogers E M. Diffusion of innovations. NY, NY. Free Press, A division of Simon and Schuster, Inc.2003.

28. Sahin I. Detailed Review of Rogers Diffusion of innovation and educational technology related studies based on Roger's theory. TOJET, 2006; 5(2); article 3.

29. The Joint Commission. The Joint commission reports high interest in new certification program for comprehensive stroke centers. ED Management; 2012; November, 127-130.

30. American Stroke Association \& American Heart Association Guideline. Guidelines for the early management of adults with ischemic stroke. Stroke 2007; $38: 1655-1711$

31. Rhode Island Department of Health, Rhode Island Stroke Task Force: FY 20102011Annual Report, Stroke Prevention and Treatment Act of 2009. http://www.health.ri.gov/programs/heartdiseaseandstrokeprevention/index.php. Retrieved February 13, 2013. 
32. State of Rhode Island: Department of Health Stroke Taskforce.

http://www.health.ri.gov/programs/heartdiseaseand stroke prevention/index.php.

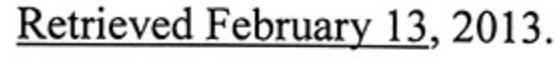




\section{Table I Stroke Quality Measures}

1. Initial National Institute of Health Stroke Scale stroke scale completed

2. Documentation that dysphagia screening was conducted prior to PO intake

3. IV thrombolytic therapy administered for eligible patients

4. IV thrombolytic therapy given within 3 hours of arrival or 2 hours of last known well

5. Documentation for not giving IV thrombolytic therapy within 3 hours

6. DVT/VTE prophylaxis initiated by end of day two or documented as contraindicated

7. Statins prescribed at discharge or documented as contraindicated

8. Antiplatelets administered by end of day two or documented as contraindicated

9. Antiplatelets prescribed at discharge or documented as contraindicated

10. Patient has atrial fibrillation or flutter history documented and was placed on anticoagulants at discharge or documented as contraindicated

11. Stroke education documented as provided to the patient and or family regarding: risk factors, EMS, medications, stroke warnings, follow up after discharge 
Table II

Hospital and Patient Demographic Characteristics

\begin{tabular}{|c|c|c|c|c|}
\hline & $\begin{array}{l}\text { Intervention } \\
\text { Site }\end{array}$ & $\begin{array}{l}\text { Intervention } \\
\text { Site }\end{array}$ & Control Site & Control Site \\
\hline Time Period & $\begin{array}{l}\text { Pre- } \\
\text { Intervention } \\
\text { June } 2005 \text { - } \\
\text { May } 2008\end{array}$ & $\begin{array}{l}\text { Post- } \\
\text { Intervention } \\
\text { June } 2008 \text { - } \\
\text { May2010 }\end{array}$ & $\begin{array}{l}\text { No } \\
\text { intervention } \\
\text { June } 2005- \\
\text { May } 2008\end{array}$ & $\begin{array}{l}\text { No } \\
\text { intervention } \\
\text { June 2008 - } \\
\text { May2010 }\end{array}$ \\
\hline Beds & 247 & 247 & 719 & 719 \\
\hline LOS & 4.4 mean & 5.6 mean & 5.0 mean & 4.7 mean \\
\hline $\begin{array}{l}\text { Annual } \\
\text { average }\end{array}$ & 448 & 448 & 947 & 947 \\
\hline Mean age & 73 & 72 & 68 & 69 \\
\hline Gender & $\begin{array}{l}\text { M- } 42 \% \\
\text { F- } 58 \%\end{array}$ & $\begin{array}{l}\text { M- } 52 \% \\
\text { F- } 48 \%\end{array}$ & $\begin{array}{l}\text { M-51\% } \\
\text { F-49\% }\end{array}$ & $\begin{array}{r}\text { M- } 52 \% \\
\text { F- } 48 \% \\
\end{array}$ \\
\hline Race/ethnicity & $\begin{array}{l}\text { W- } 83 \% \\
\text { B- } 8 \% \\
\text { O- } 9 \%\end{array}$ & $\begin{array}{l}\text { W-90\% } \\
\text { B-7\% } \\
\text { O-3\% }\end{array}$ & $\begin{array}{l}\text { W- } 82 \% \\
\text { B-12\% } \\
\text { O-6\% }\end{array}$ & $\begin{array}{l}\text { W- } 81 \% \\
\text { B- } 11 \% \\
\text { O- } 8 \%\end{array}$ \\
\hline $\begin{array}{l}\text { Illness } \\
\text { Severity }\end{array}$ & 2.3 mean & 2.5 mean & 2.1 mean & 2.5 mean \\
\hline Insured & $\begin{array}{l}\text { Insured- } 95 \% \\
\text { Uninsured - } 5 \%\end{array}$ & $\begin{array}{l}\text { Insured } 98 \% \\
\text { Uninsured } 2 \%\end{array}$ & $\begin{array}{l}\text { Insured } 92 \% \\
\text { Uninsured } 8 \%\end{array}$ & $\begin{array}{l}\text { Insured } 95 \% \\
\text { Uninsured } 5 \%\end{array}$ \\
\hline Sample size & 85 & 89 & 84 & 93 \\
\hline
\end{tabular}

Gender: $\mathrm{M}=$ male, $\mathrm{F}=$ female

Race: $\mathrm{W}=$ white $\mathrm{B}=$ black; $\mathrm{O}=$ other (may include Hispanic, Native American, Pacific Islander, Asian, South Asian) 
Table III Comparison of Mean Scores of Stroke Quality Measures

Mann- Whitney Rank Sum Test

\begin{tabular}{|l|l|l|l|l|}
\hline & $\begin{array}{l}\text { (Pre) } \\
\text { June 2005- } \\
\text { May 2008 }\end{array}$ & $\begin{array}{l}\text { (Post) } \\
\text { June 2008- } \\
\text { May 2010 }\end{array}$ & $\begin{array}{l}\text { (Pre) } \\
\text { June 2005- } \\
\text { May 2008 }\end{array}$ & $\begin{array}{l}\text { (Post) } \\
\text { June 2008- } \\
\text { May 2010 }\end{array}$ \\
\hline Intervention Site & \multicolumn{2}{|c|}{ Control site } \\
\hline Stroke Measures & Mean & $\begin{array}{l}\text { Mean (significance of } \\
\text { difference between } \\
\text { time periods at the site })\end{array}$ & Mean & $\begin{array}{l}\text { Mean (significance of } \\
\text { difference between } \\
\text { time periods at the site) }\end{array}$ \\
\hline Dysphagia & 1.8 & $1.1^{*}(\mathrm{p}=0.001)$ & 1.8 & $1.8(\mathrm{p}=0.579)$ NS \\
\hline NIHSS & 1.7 & $1.3^{*}(\mathrm{p}=0.001)$ & 1.9 & $1.8(\mathrm{p}=0.183) \mathrm{NS}$ \\
\hline tPA administered & 2.4 & $2.7^{*}(\mathrm{p}=0.014)$ & 2.5 & $2.4(\mathrm{p}=0.452) \mathrm{NS}$ \\
\hline $\begin{array}{l}\text { tPA administered } \\
\text { in 3 hours }\end{array}$ & 2.4 & $2.7^{*}(\mathrm{p}=0.008)$ & 2.5 & $2.4(\mathrm{p}=0.413) \mathrm{NS}$ \\
\hline $\begin{array}{l}\text { Contraindications } \\
\text { to tPA documented }\end{array}$ & 1.5 & $1.2^{*}(\mathrm{p}=0.027)$ & 1.5 & $1.5(\mathrm{p}=0.867) \mathrm{NS}$ \\
\hline Statin at D/C & 1.3 & $1.0^{*}(\mathrm{p}=0.010)$ & 1.3 & $1.2(\mathrm{p}=0.059) \mathrm{NS}$ \\
\hline Antiplatelets at D/C & 1.0 & $1.0(\mathrm{p}=0.503) \mathrm{NS}$ & 1.0 & $1.0(\mathrm{p}=0.339) \mathrm{NS}$ \\
\hline Stroke Education & 1.3 & $1.0^{*}(\mathrm{p}=0.001)$ & 1.6 & $1.6(\mathrm{p}=0.632) \mathrm{NS}$ \\
\hline $\begin{array}{l}\text { Afib and on } \\
\text { anticoagulation }\end{array}$ & 2.5 & $2.4(\mathrm{p}=0.666) \mathrm{NS}$ & 2.5 & $2.5(\mathrm{p}=0.917) \mathrm{NS}$ \\
\hline $\begin{array}{l}\text { VTE/DVT by } \\
\text { hospital day 2 }\end{array}$ & 1.4 & $1.1^{*}(\mathrm{p}=0.001)$ & 1.2 & $1.2(\mathrm{p}=0.350) \mathrm{NS}$ \\
\hline $\begin{array}{l}\text { Antiplatelets by } \\
\text { hospital day 2 }\end{array}$ & 1.1 & $1.0(\mathrm{p}=0.137) \mathrm{NS}$ & 1.2 & $1.1(\mathrm{p}=0.321) \mathrm{NS}$ \\
\hline
\end{tabular}

Key

$\left({ }^{*}\right)=$ statistically significant improvement

$\mathrm{NS}=$ difference not statistically significant

NIHSS $=$ NIH Stroke Scale

tPA $=$ tissue plasminogen activator

$\mathrm{D} / \mathrm{C}=$ discharge from hospital

Afib $=$ atrial fibrillation

VTE/DVT $=$ venous thrombotic embolism / deep vein thrombus 

